\title{
Parâmetros de densidade de falhas e bandas de deformação em rochas siliciclásticas pouco consolidadas da Formação Resende, Eoceno, Bacia de Volta Redonda, estado do Rio de Janeiro
} Density parameters of faults and deformation bands in poorly
lithified siliciclastic rocks of the Resende Formation, Eocene,
Volta Redonda Basin, Rio de Janeiro State, Southeastern Brazil

\author{
Bernardo Oliveira Fiuza ${ }^{1}$ (D), Claudio Limeira Mello ${ }^{1}$ (D), Carolina da Silva Ribeiro ${ }^{1}$ \\ ${ }^{1}$ Universidade Federal do Rio de Janeiro - UFRJ, Instituto de Geociências - IGEO, Departamento de Geologia, \\ Avenida Athos da Silveira Ramos, 274, bloco G, sala G1-041, Cidade Universitária, CEP 21941-916, \\ Rio de Janeiro, RJ, BR (bernardofiuza@geologia.ufrj.br; limeira@geologia.ufrj.br; carolina.ribeiro@geologia.ufrj.br)
}

Recebido em 14 de dezembro de 2019; aceito em 31 de agosto de 2020

\begin{abstract}
Resumo
O presente estudo propôs-se a analisar parâmetros de densidade de falhas e bandas de deformação em rochas siliciclásticas da Formação Resende, tomadas como geomaterial análogo a reservatórios areníticos pouco consolidados e fraturados. O estudo foi iniciado pela confecção de uma seção geológico-estrutural (escala 1:50) de um afloramento na Bacia de Volta Redonda. Essa etapa foi realizada com o auxílio de uma malha $2 \times 2 \mathrm{~m}$ fixada sobre o afloramento. Baseado na seção geológico-estrutural, foi confeccionado um mapa de densidade de estruturas. Posteriormente, foram realizados levantamentos de parâmetros de densidade das estruturas de deformação por meio dos métodos de scanlines lineares e de amostragem em janela retangular. $\mathrm{O}$ afloramento é constituído de camadas lenticulares de arenitos e conglomerados estratificados, intercaladas a camadas tabulares e lenticulares de lutitos maciços, com espessuras decimétricas, havendo ainda intervalos de brechas intraformacionais. Duas falhas principais (F1 e F2) foram reconhecidas, de caráter normal, com orientação NE-SW e mergulhos para sentidos opostos, formando um gráben. Associadas a essas falhas encontram-se zonas de elevada concentração de bandas de deformação e falhas sintéticas e antitéticas. Os parâmetros de densidade revelaram um controle litológico na distribuição das estruturas. Os maiores valores de densidade são encontrados nos arenitos médios a grossos, enquanto os menores valores estão associados aos litotipos ricos em argila, como os lutitos, os arenitos lamosos e as brechas intraformacionais. Os parâmetros de densidade mostraram maior deformação do bloco abatido (gráben), associada a uma densidade de estruturas mais contínua nessa região.
\end{abstract}

Palavras-chave: Deformação tectônica rúptil; Estratigrafia mecânica; Densidade de estruturas de deformação.

\begin{abstract}
This study aimed to analyze density parameters of faults and deformation bands in siliciclastic rocks of the Resende Formation, taken as a geomaterial analogous to poorly lithified and fractured sandstone reservoirs. The study was initiated by the construction of a geological-structural section (scale 1:50) of an outcrop in the Volta Redonda Basin. This methodological stage was carried out with the help of a 2 by 2 meter mesh fixed on the outcrop. Based on the geological-structural section, a density map of deformation structures was created. After that, density parameters of deformation structures were measured applying linear scanlines and rectangular window sampling methods. The outcrop is composed by decimetric lenticular layers of stratified sandstones and conglomerates interbedded with tabular and lenticular layers of massive mudstones, with decametric thicknesses, with intervals of intraformational breccia. Two main NE-SW-striking normal faults (F1 and F2) with opposite dip directions were recognized, forming a graben. These main faults are associated with high density clusters of deformation bands and synthetic and antithetic faults. The density parameters revealed a lithologic control in the distribution of deformation structures. The highest density values are found in medium to coarse grained sandstones, while the lowest values are associated with clay-rich lithotypes, such as the mudstones, muddy sandstones and intraformational breccias. The density parameters showed greater deformation in the hanging-wall (graben), related to a more continuous structure distribution in this region.
\end{abstract}

Keywords: Brittle tectonic deformation; Mechanical stratigraphy; Deformation structures density. 


\section{INTRODUÇÃO}

A presença de estruturas tectônicas rúpteis, como falhas e bandas de deformação, tem influência direta nas características texturais de rochas siliciclásticas deformadas (Aydin e Johnson, 1978), levando a alterações da porosidade e da permeabilidade, responsáveis por variações significativas no fluxo de fluidos (Fisher e Knipe, 1998; Gibson, 1998; Pei et al., 2015; Fossen et al., 2017).

Em se tratando de reservatórios areníticos pouco consolidados, a identificação e a caracterização de zonas deformadas são um assunto especialmente complexo, uma vez que essas estruturas ocorrem de forma pervasiva nesse tipo de rocha e frequentemente em escalas não detectáveis dentro dos limites de resolução dos dados sísmicos ou de poços (Wibberley et al., 2008). Dessa forma, a predição da distribuição espacial de falhas e bandas de deformação ao longo dos domínios estruturais de uma zona de falha em reservatórios siliciclásticos é um constante desafio para a indústria.

Diversos fatores podem influenciar a forma como as estruturas de deformação se distribuem, como a história evolutiva e a geometria das zonas de falhas, bem como os litotipos afetados (Heynekamp et al., 1999; Fossen et al., 2017). Schueller et al. (2013), com base em dados de campo compilados de diversas zonas de falhas normais que afetam arenitos porosos, observaram que as zonas de dano se mostraram estatisticamente mais espessas nos blocos abatidos do que nos blocos soerguidos, destacando também uma diminuição logarítmica da frequência de bandas de deformação com o aumento da distância em relação ao núcleo de falha.

O estudo de afloramentos como análogos é uma ferramenta comumente utilizada na indústria como base para a parametrização de propriedades de reservatórios (Howell et al., 2014), na busca por soluções para as dificuldades decorrentes do acesso limitado às informações geológicas em subsuperfície. Nesse contexto, os arenitos da Formação Resende têm sido considerados em trabalhos recentes (Maciel et al., 2017; Rotava, 2017; Galvão, 2018; Vogel et al., 2019) como um geomaterial análogo a reservatórios siliciclásticos pouco consolidados e fraturados presentes nas bacias da margem continental do Sudeste do Brasil, tais como os reservatórios areníticos do Maastrichtiano das bacias de Campos e Santos. A característica pouco consolidada dessa unidade litoestratigráfica (Ramos et al., 2006) e sua expressiva deformação tectônica, tendo sido submetida a pelo menos três fases de deformação (Riccomini, 1989; Riccomini et al., 2004; Sanson et al., 2006; Negrão et al., 2015), qualificam-na para esse tipo de investigação.

O presente estudo analisou a distribuição espacial de falhas e bandas de deformação em rochas siliciclásticas pouco consolidadas, utilizando parâmetros de densidade dessas estruturas ao longo de um afloramento da Formação Resende na Bacia de Volta Redonda, anteriormente investigado por
Maciel et al. (2017), Rotava (2017), Galvão (2018) e Vogel et al. (2019). O objetivo foi reconhecer possíveis fatores controladores da distribuição das estruturas de deformação nesse tipo de rocha e, assim, contribuir para melhor predição da sua ocorrência em subsuperfície.

\section{CONTEXTO GEOLÓGICO}

A Bacia de Volta Redonda, situada no extremo oeste do estado do Rio de Janeiro, é uma depressão tectônica de origem distensiva, com geometria de gráben assimétrico, alongada segundo um eixo de direção NE-SW (Negrão et al., 2015), que integra um conjunto de bacias tafrogênicas continentais de idade paleogênica que se distribuem do Paraná ao Rio de Janeiro (Riccomini et al., 2004). Essas bacias sedimentares estão inseridas em uma importante feição geotectônica denominada por Riccomini (1989) como Rift Continental do Sudeste do Brasil (RCSB), integrando, com as bacias de Resende, Taubaté e São Paulo, o Segmento Central do RCSB. Zalán e Oliveira (2005) ampliaram a abrangência da região envolvida pela evolução tectônica cenozoica da margem Sudeste do Brasil, definindo o Sistema de Riftes Cenozoicos do Sudeste do Brasil (SRCSB), no qual a Bacia de Volta Redonda está inserida no Rifte do Paraíba do Sul.

O embasamento da Bacia de Volta Redonda é constituído essencialmente de ortognaisses paleoproterozoicos, rochas metassedimentares neoproterozoicas e granitoides neoproterozoicos a eopaleozoicos, relacionados à porção central da Faixa Ribeira, na Província Mantiqueira. Essas rochas encontram-se dispostas sob a forma de corpos alongados segundo uma orientação NE-SW, acompanhando o trend estrutural regional da Faixa Ribeira. Ocorrem ainda rochas ígneas alcalinas intrusivas, com idades variando do Cretáceo ao Eoceno, sob a forma de maciços e diques (Heilbron et al., 2007; Heilbron et al., 2016).

A Formação Resende constitui o registro da principal fase de sedimentação da Bacia de Volta Redonda (Figura 1) e das bacias que compõem o Segmento Central do RCSB (Riccomini et al., 2004; Sanson et al., 2006; Negrão et al., 2015), sendo geralmente encontrada em inconformidade sobre o embasamento pré-cambriano. Os depósitos dessa unidade litoestratigráfica são, geralmente, pouco consolidados, caracterizados por um predomínio de arenitos feldspáticos estratificados, com intercalações de conglomerados finos e lamitos esverdeados. Ocorrem ainda conglomerados mal selecionados e arenitos lamosos. Esses depósitos são associados a sistemas fluviais de padrão entrelaçado e a sistemas de leques aluviais (Sanson et al., 2006; Negrão et al., 2015).

A evolução da Bacia de Volta Redonda está relacionada a sucessivas fases tectônicas reconhecidas no RCSB, desde a sua formação, em uma fase de distensão NW-SE eocênica 


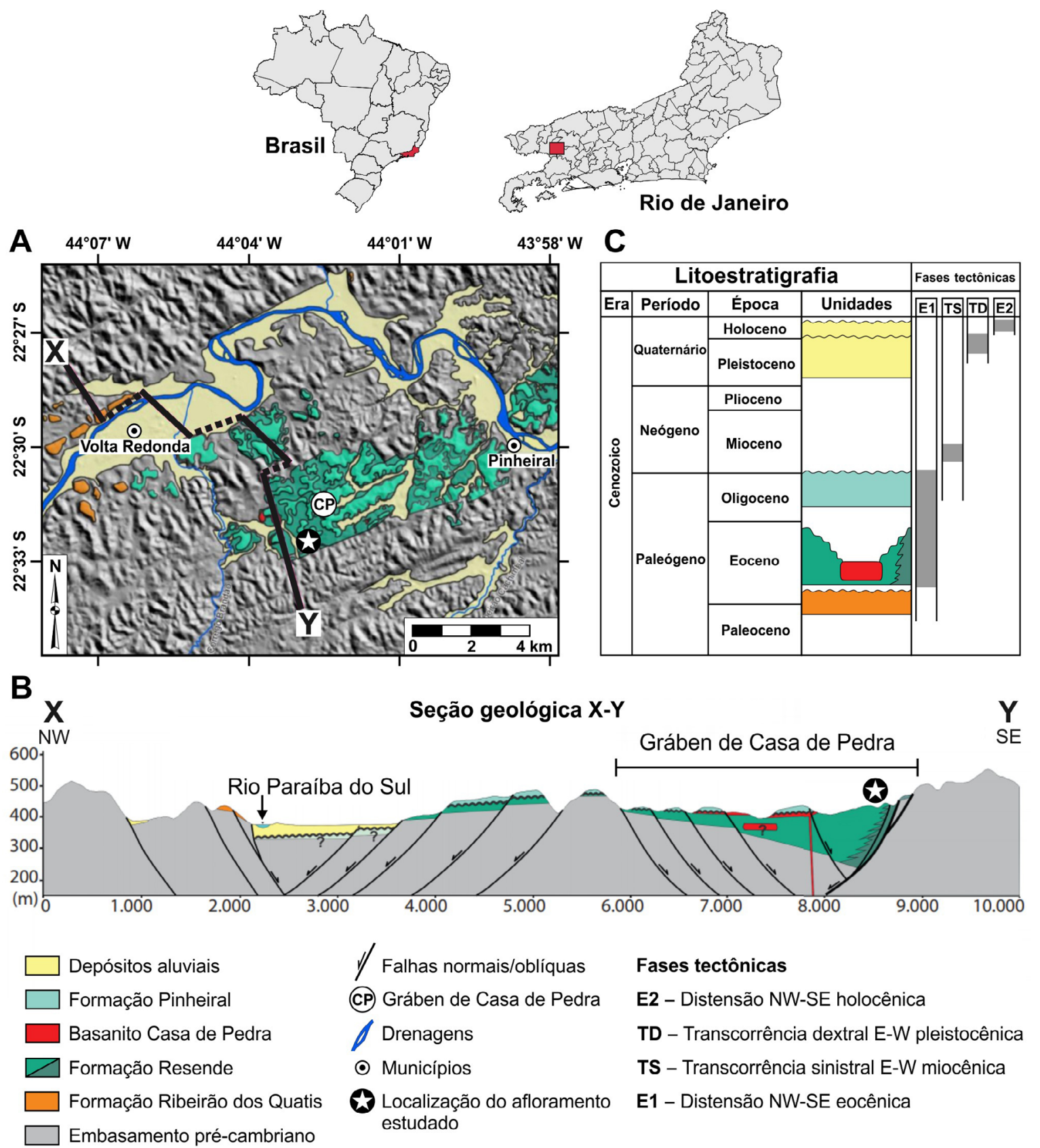

Fonte: adaptado de Negrão et al. (2015).

Figura 1. (A) Recorte do mapa geológico da Bacia de Volta Redonda, destacando a região do Gráben de Casa de Pedra, com a localização da seção geológica esquemática apresentada em (B) e do afloramento investigado no presente estudo. (B) Seção geológica esquemática, transversal à Bacia de Volta Redonda, mostrando uma conformação geral de hemigráben deformado. Destaca-se, também, a localização do afloramento. (C) Coluna litoestratigráfica simplificada e fases tectônicas reconhecidas na região da Bacia de Volta Redonda.

(E1), tendo sido submetida a pelo menos três fases de deformação (Figura 1): transcorrência sinistral E-W miocênica (TS); transcorrência dextral E-W pleistocênica (TD); e distensão NW-SE holocênica (E2) — Sanson et al. (2006), Negrão et al. (2015).
O afloramento estudado da Formação Resende está situado próximo da borda sul (borda de falha) do Gráben de Casa de Pedra (Figura 1), principal depocentro da Bacia de Volta Redonda. Localiza-se em um terreno particular à margem da Rodovia do Contorno, cujo acesso pode ser feito 
por meio da Rodovia dos Metalúrgicos (VRD-001, ao sul) ou da Rodovia Lúcio Meira (BR-393, ao norte). As coordenadas geográficas da localidade são: $22^{\circ} 32^{\prime} 25^{\prime}$ "de latitude

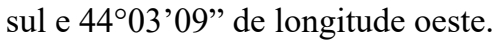

Entre os principais resultados já obtidos no estudo desse afloramento, Maciel et al. (2017) consideraram que a atuação de diferentes fases tectônicas, com regimes de esforços distintos (atribuídos às fases TS, TD e E2 propostas por Sanson et al., 2006 e Negrão et al., 2015), favoreceu o desenvolvimento de elementos estruturais reconhecidos na literatura como feições condicionantes da dinâmica do fluxo de fluidos em reservatórios (núcleos de falhas, zonas de dano e zonas de bandas de deformação). Rotava (2017) realizou a caracterização microestrutural das bandas de deformação identificadas por Maciel et al. (2017), classificando-as como bandas cataclásticas, predominantemente, e bandas de desagregação. Tanto Maciel et al. (2017) quanto Rotava (2017) reconheceram variações no padrão de cimentação por óxidos de ferro, indicando estarem relacionadas à presença desses elementos estruturais controlando a percolação de fluidos meteóricos.

Galvão (2018) analisou o papel das falhas e bandas de deformação na modificação do fabric de uma camada de arenito da Formação Resende no afloramento. Os indicativos granulométricos, texturais, composicionais e microestruturais apontaram que a alteração foi efetiva em direção às falhas e bandas de deformação, com maior deformação relacionada à zona de falha. Notou ainda uma variação desses aspectos comparando-se os blocos soerguidos e abatidos da falha, indicando maior deformação no bloco abatido.

Vogel et al. (2019) analisaram o impacto de falhas e bandas de deformação na porosidade e na permeabilidade de arenitos da Formação Resende expostos nesse afloramento. Por intermédio de imagens tomográficas e microtomográficas e ensaios de petrofísica básica, os autores identificaram maior compactação dos arenitos nas regiões afetadas pelas estruturas de deformação. Valores menores de porosidade e permeabilidade foram verificados nos arenitos mais deformados, associados a menor granulometria e maior compactação.

\section{MÉTODOS}

Os métodos utilizados no desenvolvimento deste estudo envolveram, basicamente, duas etapas: a elaboração de uma seção geológico-estrutural detalhada (escala 1:50) do afloramento estudado; e a obtenção de parâmetros de densidade das estruturas de deformação. O conceito de "parâmetros de densidade" é usado neste estudo para se referir a valores que refletem a abundância de estruturas de deformação, conforme método sistematizado por Dershowitz e Herda (1992), Tabela 1, englobando genericamente outras denominações utilizadas na literatura, como frequência e intensidade.

Para a confecção da seção geológico-estrutural foi inicialmente fixada no afloramento uma malha $2 \times 2 \mathrm{~m}$, abrangendo toda a área a ser representada (Figura 2). A malha foi construída com fios de sisal e fixada com pregos na superfície do talude, com controle rigoroso dos espaçamentos horizontais e verticais, com uso de trena e metro articulado. A demarcação dos níveis horizontais foi baseada no princípio dos vasos comunicantes. Em razão da inclinação do afloramento (entre 45 e $50^{\circ}$ ), os espaçamentos verticais (sempre de $2 \mathrm{~m}$ ) foram demarcados aplicando-se o princípio dos triângulos retângulos. Esse mesmo princípio foi utilizado para medir a diferença de altura entre dois pontos quaisquer.

Utilizando a malha como referência, a seção foi desenhada em papel milimetrado ao longo de várias etapas de trabalho de campo, a partir da identificação dos litotipos, do acompanhamento dos contatos litológicos e da caracterização dos elementos estruturais (núcleos de falha, superfícies de falha, bandas de deformação e feições de clay smear). A seção representa a projeção vertical das relações estratigráficas e estruturais identificadas no afloramento. A versão final do desenho foi escaneada e editada em software de edição de imagens.

Tabela 1. Parâmetros de densidade de estruturas classificados de acordo com a dimensão da aquisição dos dados e com as dimensões das estruturas, segundo método sistematizado por Dershowitz e Herda (1992).

\begin{tabular}{|c|c|c|c|}
\hline & & \multicolumn{2}{|c|}{ Dimensão da aquisição } \\
\hline & & 1: Linha & 2: Área \\
\hline \multirow{3}{*}{$\begin{array}{l}\text { Dimensões das } \\
\text { estruturas }\end{array}$} & $\begin{array}{l}\text { 0: Número de } \\
\text { estruturas }\end{array}$ & $\begin{array}{c}\text { P10 } \\
\text { Número de estruturas por unidade } \\
\text { de comprimento }(1 / \mathrm{m})\end{array}$ & $\begin{array}{c}\text { P20 } \\
\text { Número de estruturas por } \\
\text { unidade de área }\left(1 / \mathrm{m}^{2}\right)\end{array}$ \\
\hline & 1: Comprimento & $\begin{array}{c}\text { P11 } \\
\text { Comprimento acumulado das estruturas } \\
\text { por unidade de comprimento (\%) }\end{array}$ & $\begin{array}{c}\text { P21 } \\
\text { Comprimento acumulado das estruturas } \\
\text { por unidade de área }\left(\mathrm{m} / \mathrm{m}^{2}\right)\end{array}$ \\
\hline & 2: Área & - & $\begin{array}{c}\text { P22 } \\
\text { Área das estruturas por unidade de área (\%) }\end{array}$ \\
\hline
\end{tabular}



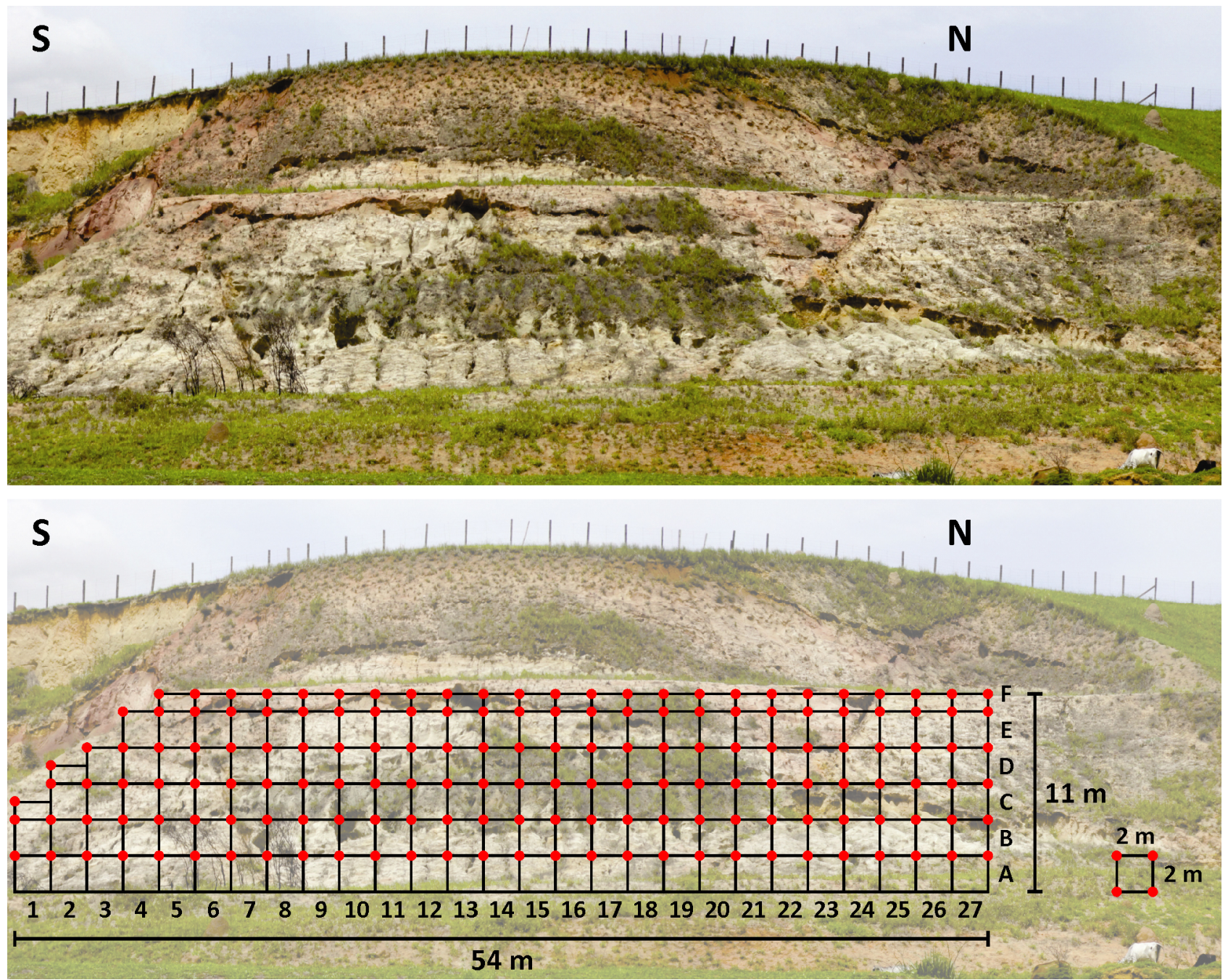

Figura 2. Fotografia do afloramento estudado e representação esquemática da projeção vertical da malha $2 \times 2 \mathrm{~m}$ fixada como guia para a elaboração da seção geológico-estrutural e para a aquisição de atributos das estruturas de deformação.

Durante as etapas de trabalho de campo, foram feitas coletas sistemáticas de dados estruturais ao longo do afloramento, por meio da medição das atitudes das bandas de deformação e das superfícies de falha. Quando presentes, as atitudes das estrias associadas às superfícies das falhas também foram medidas, caracterizando-se as estruturas de deformação do ponto de vista geométrico e cinemático. Os pares falha-estria foram analisados com relação aos campos de paleotensões geradores da deformação, com a aplicação do método dos diedros retos (Angelier, 1994), utilizando o programa Win-Tensor (Delvaux e Sperner, 2003).

A obtenção dos dados para o cálculo de parâmetros de densidade das falhas e bandas de deformação que afetam os depósitos foi realizada por meio dos métodos de scanlines lineares e de amostragem em janela retangular (Priest, 1993;
Watkins et al., 2015). O método de scanlines lineares (ou linhas de levantamento estrutural) consiste, basicamente, na aquisição dos atributos ao longo de linhas de varredura no afloramento, enquanto no método de amostragem em janela retangular a aquisição é realizada em áreas retangulares. Neste estudo, foram observados os seguintes atributos: tipo de estrutura; quantidade; espessura da estrutura; espaçamento entre as estruturas (scanlines lineares); comprimento das estruturas (amostragem em áreas retangulares); e litotipo. Esses atributos foram obtidos em duas scanlines lineares e em duas áreas retangulares. As posições das scanlines lineares foram escolhidas de modo a comparar a densidade de estruturas de deformação em diferentes conjuntos litológicos. A escolha da localização das áreas retangulares buscou representar as regiões onde as zonas de dano das 
falhas principais (F1 e F2) eram mais expressivas, contemplando também aspectos litológicos distintos.

Com base na seção geológico-estrutural, foi confeccionado, ainda, um mapa de densidade de estruturas utilizando a ferramenta Line Density do software ArcGIS ${ }^{\circledR}$. Essa ferramenta calcula a densidade de linhas que, nesse caso, representam as estruturas de deformação. Como o arquivo de entrada possui as dimensões reais do afloramento, o resultado obtido é um mapa em que cada célula do arquivo de saída recebe uma cor de acordo com o seu valor, na unidade $\mathrm{m} / \mathrm{m}^{2}$, representando o parâmetro de densidade P21 (Tabela 1).

\section{RESULTADOS}

\section{Seção geológico-estrutural}

A seção geológico-estrutural produzida é composta de camadas lenticulares de arenitos e conglomerados estratificados, camadas tabulares e lenticulares de lutitos maciços e laminados, e camadas lenticulares de brechas intraformacionais maciças e estratificadas (Figura 3). As camadas apresentam espessuras decimétricas. Os intervalos litológicos, típicos da Formação Resende, encontram-se dispostos em sucessões

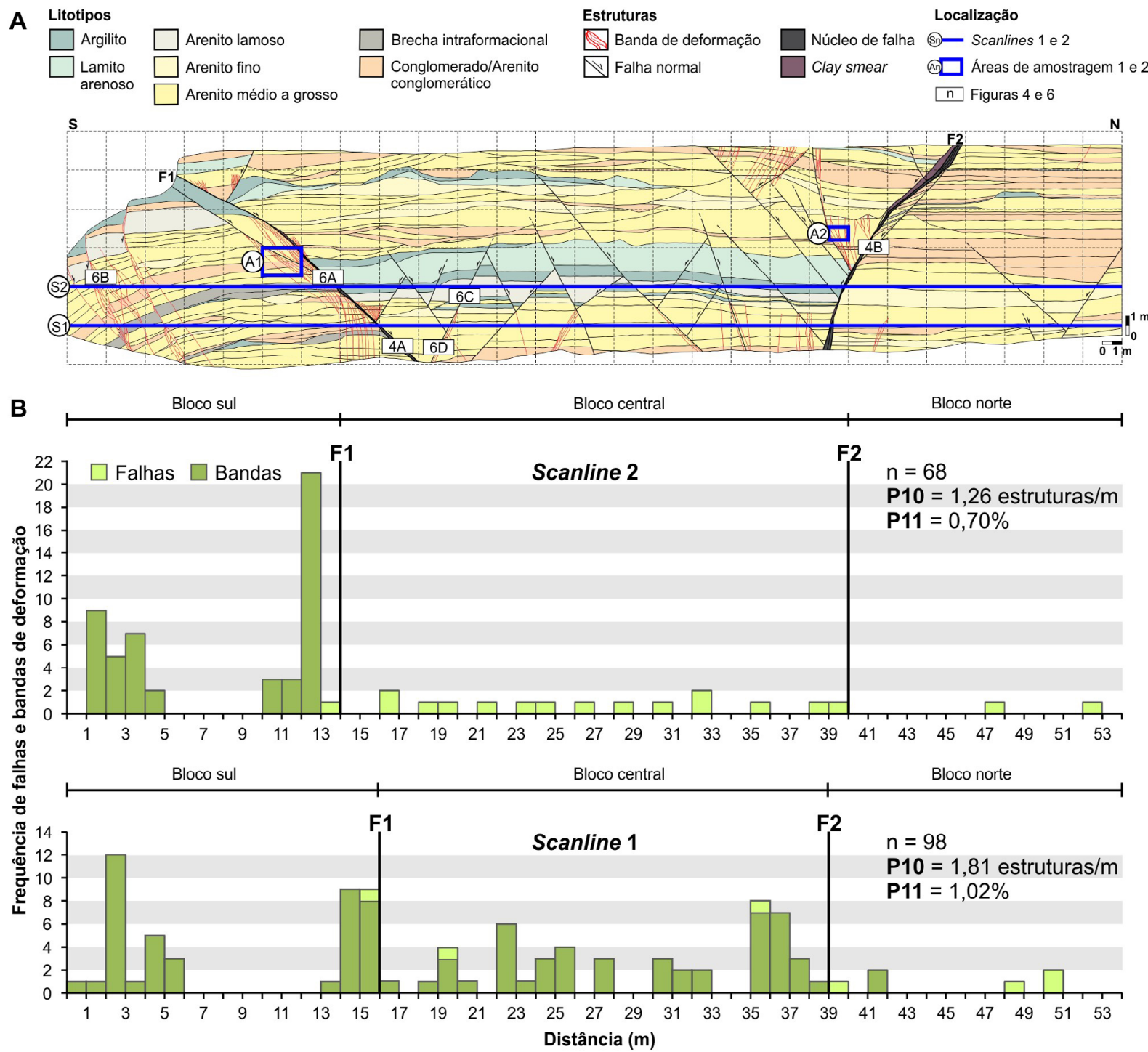

F1 e F2: falhas principais.

Figura 3. (A) Seção geológico-estrutural (escala original 1:50) elaborada, com a localização das scanlines 1 (S1) e 2 (S2), das áreas de amostragem 1 (A1) e 2 (A2), e das imagens apresentadas nas Figuras 4 e 6 . Também está indicada a projeção vertical da malha utilizada como base para a confecção da seção. (B) Gráficos de frequência de falhas e bandas de deformação gerados a partir dos dados obtidos por meio das scanlines 1 e 2 . Destaca-se a posição em que as scanlines interceptam as falhas F1 e F2, separando os dados referentes aos blocos sul, central e norte. 
granodecrescentes ascendentes, completas ou incompletas, geralmente interrompidas por contatos erosivos, sendo comum a presença de níveis de seixos e intraclastos de argila na base dos ciclos. Esses depósitos são associados a canais fluviais de padrão entrelaçado com planícies de inundação restritas.

Os depósitos são afetados por duas falhas principais (F1 e F2), de caráter normal e rejeitos métricos, que seccionam toda a seção e a dividem em três blocos (sul, central e norte). As duas falhas apresentam orientação ENE-WSW, com mergulhos para sentidos opostos, formando um gráben (Figuras 3 e 4). As falhas F1 e F2 são zonas de deformação complexas, sendo compostas de núcleos de falha e zonas de dano. Os núcleos dessas falhas apresentam larguras variadas, sendo mais restritos nas camadas lutíticas e mais desenvolvidos nos arenitos médios a grossos.

Falhas secundárias de orientação NE-SW, de caráter normal e com rejeitos decimétricos, ocorrem associadas às falhas F1 e F2, sintéticas e antitéticas, preferencialmente no bloco abatido (bloco central). Essas falhas apresentam um padrão de pares conjugados e, em sua maioria, não afetam toda a sucessão sedimentar, tendo se propagado somente até próximo ao topo de um espesso intervalo lutítico (com cerca de $2 \mathrm{~m}$ de espessura) no bloco central (Figura 3 ).

A análise de paleotensões realizada (Figura 5) indica que o conjunto das falhas descritas está associado a uma distensão NW-SE, relacionada à fase E2 de Negrão et al. (2015).

Adjacentes às falhas $\mathrm{F} 1$ e F2, nos blocos soerguidos e no bloco abatido, ocorrem estruturas de deformação com espessuras milimétricas, caracterizadas por uma redução granulométrica, coloração mais clara e relevo positivo, interpretadas como bandas de deformação (Figura 3). Essas estruturas compõem as zonas de dano das falhas principais, exceto nos lutitos, onde não ocorrem bandas de deformação. Nas zonas de dano, as bandas de deformação apresentam espaçamentos de ordem milimétrica a centimétrica, aumentando conforme se afasta das falhas principais (Figura 6A).

No bloco sul da seção há uma região intensamente deformada, com cerca de $5 \mathrm{~m}$ de largura, que se estende da base até o topo, onde podem ser observadas ao menos três zonas
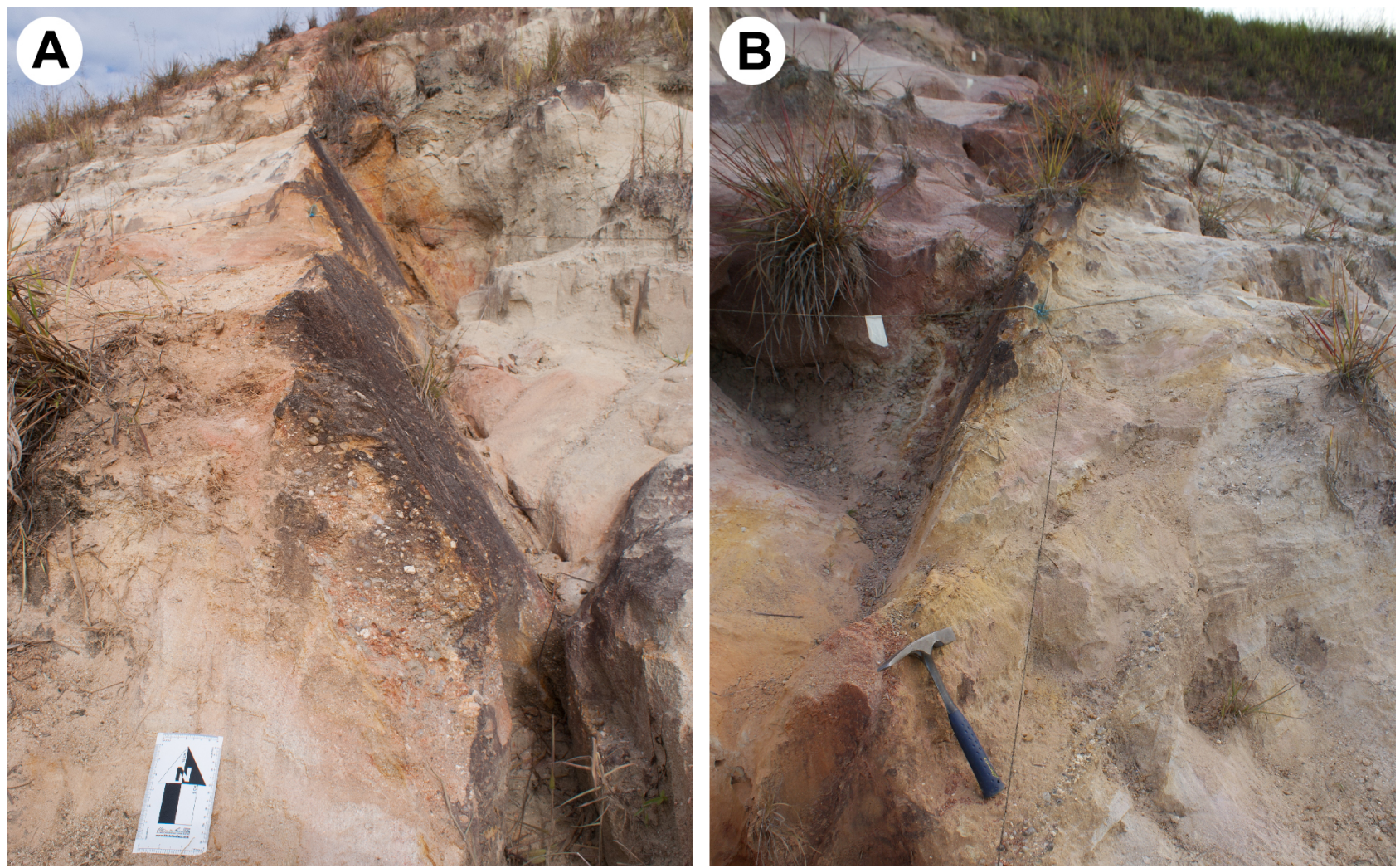

Figura 4. (A) Superfície da falha F1, com atitude $330^{\circ} / 55^{\circ}$ (dip-dip). (B) Superfície da falha F2, com atitude $165^{\circ} / 60^{\circ}$ (dip-dip). As estrias presentes nas superfícies das duas falhas, bem como os padrões de rugosidade, as estruturas de arrasto de camadas e as relações estratigráficas, indicam movimentação normal, como também caracterizado por Maciel et al. (2017) no mesmo afloramento. Destaca-se a intensa ferruginização associada às superfícies das falhas, evidenciada pela coloração marrom-alaranjada, conferindo resistência à erosão e demonstrando a influência estrutural no fluxo de fluidos. Ver localização na Figura 3A. 
A

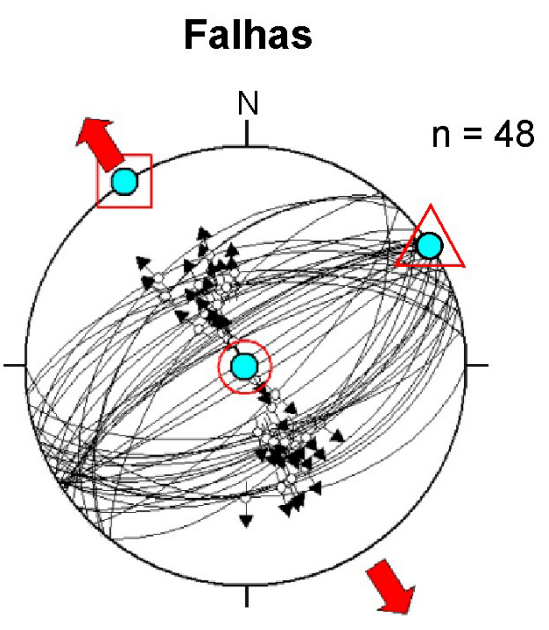

B

\section{Bandas de deformação}

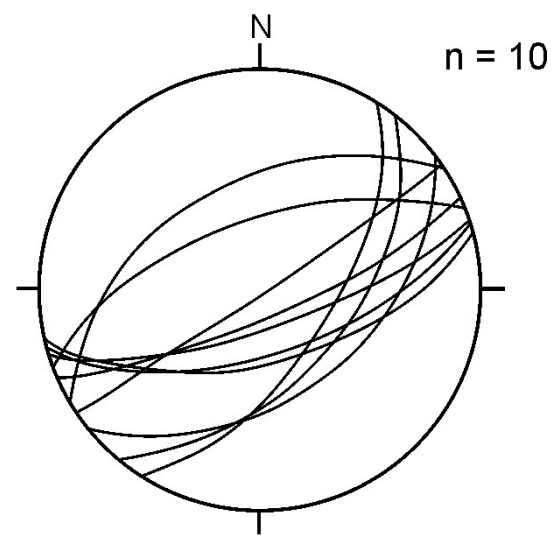

Figura 5. (A) Diagrama de paleotensões (projeção estereográfica de igual área e hemisfério inferior) gerado a partir da análise dos pares falha/estria, indicando um campo de esforços distensivo NW-SE, relacionado à fase E2 de Negrão et al. (2015). (B) Projeção estereográfica (igual área e hemisfério inferior) das superfícies das bandas de deformação medidas no afloramento.

de concentração de bandas de deformação (clusters), além de bandas individuais (Figuras 3 e 6B).

As bandas de deformação apresentam orientação NE-SW, acompanhando o trend geral das falhas (Figura 5).

A forma de ocorrência de falhas e bandas de deformação no afloramento indica uma relação com os litotipos afetados por essas estruturas. Como exemplo dessa relação, as falhas secundárias no bloco central ocorrem como superfícies de deslizamento nítidas nos lutitos, nos arenitos lamosos e nos arenitos finos (Figura 6C), e com aspecto difuso nos arenitos médios a grossos e nos conglomerados, relacionando-se com faixas de larguras decimétricas de bandas de deformação (Figura 6D). No bloco sul da seção, são observados clusters de até $50 \mathrm{~cm}$ de largura nos arenitos médios a grossos e nos conglomerados que, ao atravessarem litotipos ricos em argila, como lutitos, arenitos lamosos e brechas intraformacionais, adelgaçam-se, formando zonas de até $20 \mathrm{~cm}$ de largura ou até mesmo simples superfícies, no caso dos lutitos.

\section{Parâmetros de densidade de falhas e bandas de deformação}

Os resultados dos cálculos de parâmetros de densidade das estruturas de deformação (falhas e bandas de deformação) que afetam as rochas da Formação Resende no afloramento estudado podem ser divididos, pela dimensão da aquisição dos dados, entre os obtidos em linha (scanlines lineares) ou em área (amostragem em áreas retangulares e mapa de densidade de estruturas de deformação).

\section{Scanlines lineares}

Os dados obtidos em linha consistem em duas scanlines coletadas em campo, com $54 \mathrm{~m}$ de comprimento cada uma. A scanline 1 foi coletada onde predominam arenitos médios a grossos, e a scanline 2 passa, em grande parte, por intervalos de lutitos, arenitos lamosos e brechas intraformacionais (Figura 3).

As scanlines 1 e 2 apresentam valores máximos de frequência relacionados à região de zonas de bandas de deformação do bloco sul e às zonas de dano de F1 (bloco soerguido) e F2 (bloco abatido - somente na scanline 1), sendo o bloco central afetado de maneira contínua.

Na scanline 1, foram identificadas 98 estruturas, sendo 7 $(7,1 \%)$ falhas e $91(92,9 \%)$ bandas de deformação, enquanto na scanline 2 foram identificadas 68 estruturas, sendo 18 $(26,5 \%)$ falhas e 50 (73,5\%) bandas de deformação. O número total de estruturas, portanto, foi 1,4 vez maior na scanline 1 do que na scanline 2 , o que se reflete também no parâmetro P10, calculado, respectivamente, em 1,81 e 1,26 estruturas por metro (Tabela 2).

Com base no somatório das espessuras das estruturas identificadas na coleta de campo, calculou-se também o parâmetro P11, indicando que esse valor representa 1,02\% dos $54 \mathrm{~m}$ de comprimento da scanline 1 e $0,70 \%$ da scanline 2 (Tabela 2).

A scanline 1, localizada onde predominam arenitos médios a grossos, apresenta número total de estruturas e, consequentemente, parâmetro P10 (número de estruturas por metro) - maior do que a scanline 2, que atravessa, em grande parte, intervalos de lutitos, arenitos lamosos e brechas intraformacionais. A scanline 1 também apresenta quantidade maior de bandas de deformação do que a scanline 2 , entretanto a quantidade de falhas é menor. Isso pode 

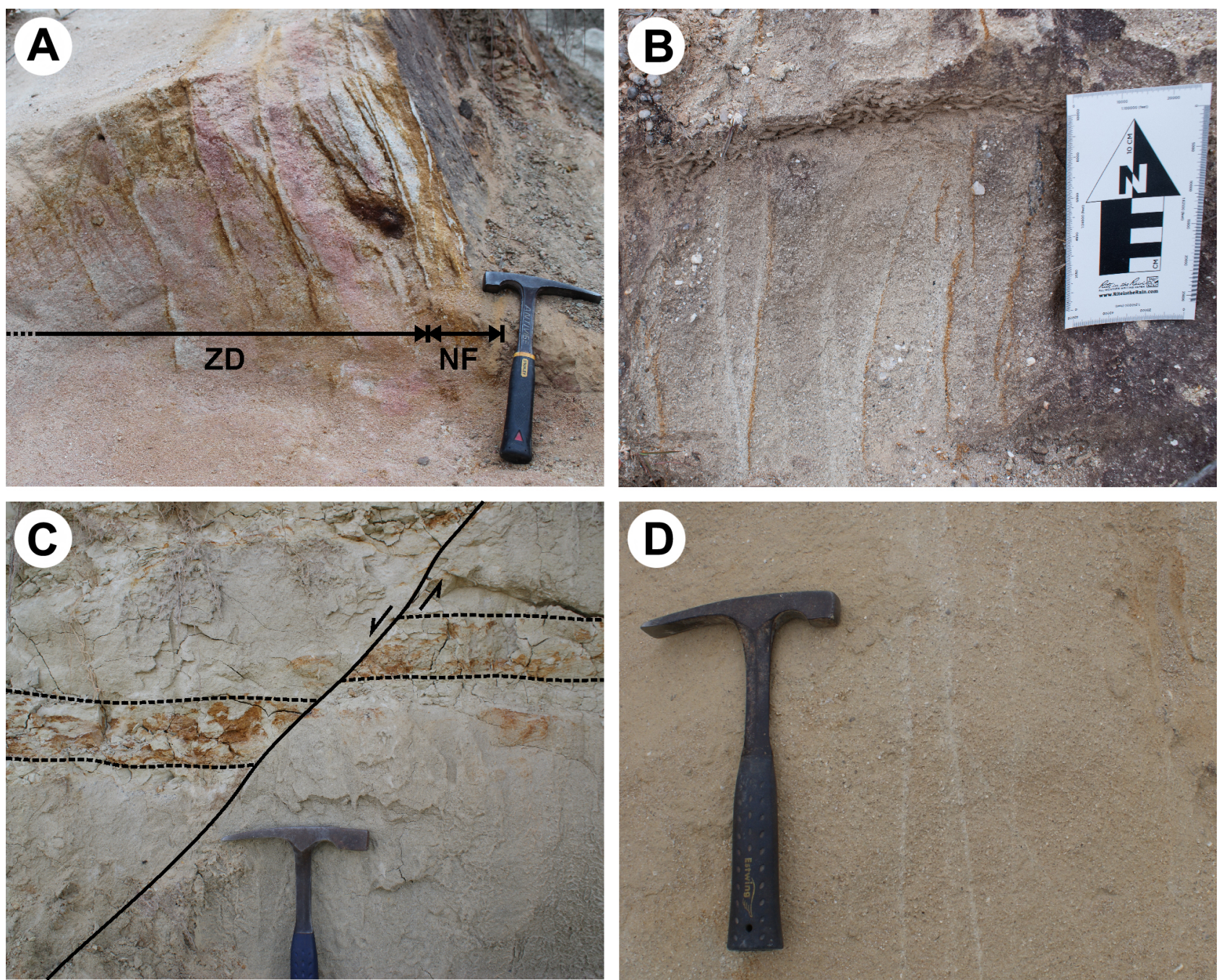

Figura 6. (A) Corte transversal à falha F1, em arenitos médios a grossos do bloco soerguido, mostrando bandas de deformação mais frequentes próximas à superfície principal da falha (núcleo de falha - NF) e mais espaçadas conforme aumenta a distância para essa superfície (zona de dano - ZD). (B) Bandas de deformação, em detalhe, destacadas, em relação ao seu entorno, por uma coloração mais clara, diminuição granulométrica e relevo pronunciado. Nota-se o padrão de ferruginização associado aos limites das estruturas, demonstrando a influência das bandas de deformação no fluxo de fluidos. (C) Falha secundária afetando arenitos finos argilosos e lutitos arenosos. (D) Bandas de deformação, em arenitos médios a grossos, observadas ao rastrear-se o prolongamento da falha vista em (C) em camadas localizadas em posição estratigráfica inferior. Ver localização das imagens na Figura 3A.

Tabela 2. Parâmetros de densidade de estruturas obtidos por meio das scanlines 1 e 2 .

\begin{tabular}{lcc}
\hline & Scanline 1 & Scanline 2 \\
\hline Número de & 98 & 68 \\
estruturas (n) & & \\
P10 & 1,81 estruturas $/ \mathrm{m}$ & 1,26 estruturas/m \\
P11 & $1,02 \%$ & $0,70 \%$ \\
\hline
\end{tabular}

ser explicado pelo fato de muitas das falhas no bloco central terem sido caracterizadas nos intervalos lutíticos presentes acima da posição onde foi realizada a scanline 1 . Essas falhas foram, então, projetadas para intervalos areníticos abaixo, onde as rupturas não eram tão evidentes, em razão do caráter litológico, tendo sido reconhecidas mais frequentemente, durante a elaboração da scanline 1, bandas de deformação ou zonas de bandas (clusters). 
O parâmetro P11 (somatório das espessuras das estruturas por metro), obtido em campo, também foi maior na scanline 1 do que na scanline 2, representando maior percentual de rocha deformada em relação ao comprimento da scanline, o que é relacionado à menor expressão das bandas de deformação nos litotipos lamosos.

Nas duas scanlines nota-se uma tendência de diminuição da frequência de estruturas de sul, onde está localizada a borda de falha da bacia, para norte.

\section{Amostragem em áreas retangulares}

A área de amostragem 1 (A1) possui $4 \mathrm{~m}^{2}$, abrangendo arenitos grossos e conglomerados finos, moderadamente a mal selecionados, estando posicionada no bloco soerguido da falha F1, adjacente a essa estrutura (Figura 3). Nessa área foram identificadas 47 bandas de deformação, o que corresponde a 11,75 bandas de deformação por metro quadrado (parâmetro P20). O somatório do comprimento dessas estruturas, no trecho compreendido dentro da área, foi de $36,48 \mathrm{~m}$, equivalendo a $9,12 \mathrm{~m} / \mathrm{m}^{2}$ (parâmetro P21). $\mathrm{O}$ somatório das áreas dessas bandas, calculadas com base em seus comprimentos e suas espessuras, representa $2,72 \%$ da área total (parâmetro P22) (Tabela 3).

Tabela 3. Parâmetros de densidade de estruturas obtidos por meio das amostragens realizadas nas áreas 1 e 2 .

\begin{tabular}{lcc}
\hline & Área 1 & Área 2 \\
\hline P20 & 11,75 bandas de & 47 bandas de \\
& deformação $/ \mathrm{m}^{2}$ & deformação $/ \mathrm{m}^{2}$ \\
P21 & $9,12 \mathrm{~m} / \mathrm{m}^{2}$ & $23,17 \mathrm{~m} / \mathrm{m}^{2}$ \\
P22 & $2,72 \%$ & $3,24 \%$ \\
\hline
\end{tabular}

A área de amostragem 2 (A2) está localizada no bloco abatido de F2, adjacente a uma de suas falhas antitéticas (Figura 3). Possui $1 \mathrm{~m}^{2} \mathrm{e}$ abrange arenitos médios, moderadamente a bem selecionados. Nessa área foram computadas 47 bandas de deformação por metro quadrado (parâmetro P20), 23,17 m de estruturas por metro quadrado (parâmetro P21) e a área dessas bandas representa $3,24 \%$ da área total (parâmetro P22) (Tabela 3).

Comparando-se os resultados obtidos nas duas áreas, nota-se que na A2 são encontradas 4 vezes mais bandas de deformação do que na $\mathrm{A} 1$ (parâmetro P20), e 2,5 vezes em comprimento (parâmetro P21). Contudo, essa diferença não é tão grande ao considerar o percentual que a área das bandas representa em relação à área total (parâmetro P22), sendo apenas 1,2 vez maior na área 2 . Na área 1 , composta de arenitos grossos e conglomerados finos, moderadamente a mal selecionados, são encontradas bandas de deformação mais espaçadas e mais espessas em relação à área 2 , composta de arenitos médios, moderadamente a bem selecionados. Enquanto na área 1 o valor médio de espessura das estruturas é de 2,6 $\mathrm{mm}$, na área 2 é de $1,4 \mathrm{~mm}$.

\section{Mapa de densidade de estruturas de deformação}

O mapa de densidade confeccionado a partir das estruturas representadas na seção geológico-estrutural (Figura 7) refere-se à distribuição do parâmetro P21 para cada região do afloramento, representando o comprimento de estruturas existentes por unidade de área.

$\mathrm{O}$ resultado obtido apresenta valores de $\mathrm{P} 21$ que variam de 0 a $24 \mathrm{~m} / \mathrm{m}^{2}$, sendo o bloco soerguido próximo à $\mathrm{F} 1$ (até $24 \mathrm{~m} / \mathrm{m}^{2}$ ), o bloco abatido próximo à F2 (até $14 \mathrm{~m} / \mathrm{m}^{2}$ ) e a

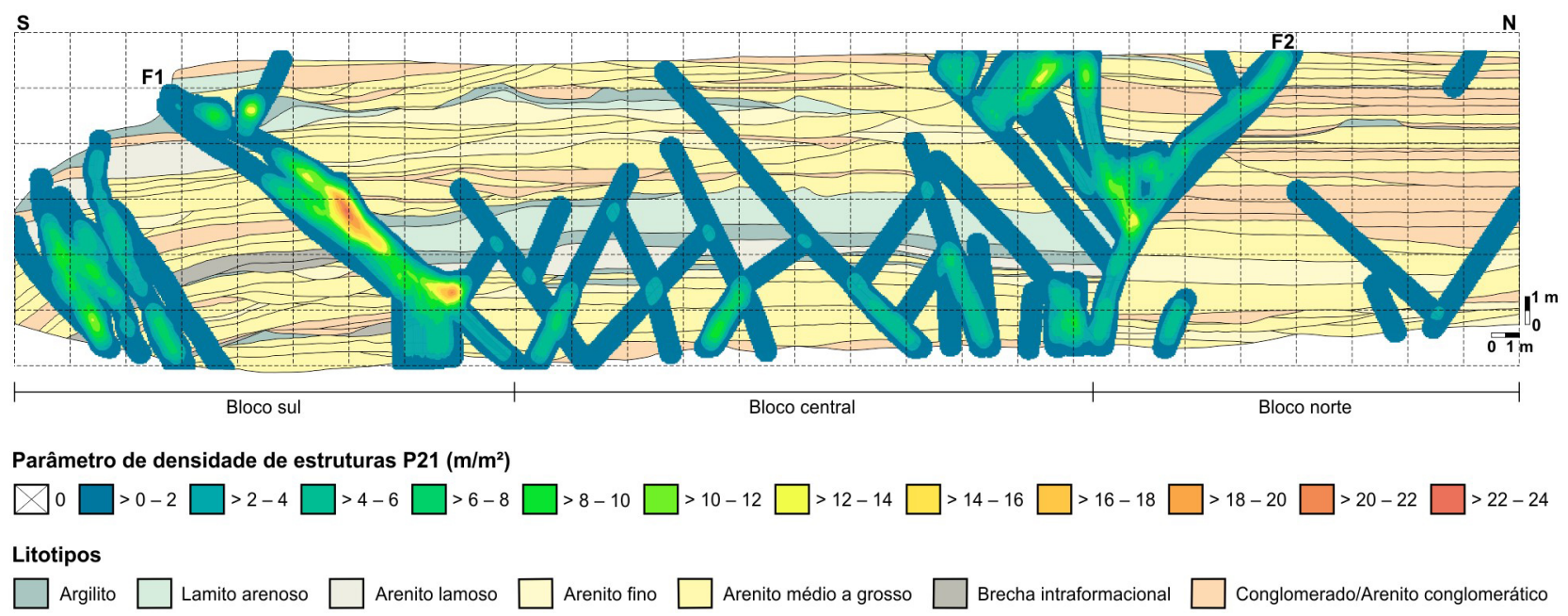

Figura 7. Mapa de densidade de estruturas calculada a partir da distribuição de estruturas na seção geológico-estrutural (escala original 1:50), correspondendo ao parâmetro P21. 
região de zonas de bandas de deformação no bloco sul (até $12 \mathrm{~m} / \mathrm{m}^{2}$ ) as porções do afloramento que apresentam os maiores valores de densidade de estruturas de deformação. O bloco central como um todo apresenta valores menores do que os observados nessas regiões, porém distribuídos de forma mais contínua.

Os maiores valores de densidade são observados nos arenitos médios a grossos e nos conglomerados, em comparação aos encontrados nos lutitos, nos arenitos lamosos, nos arenitos finos e nas brechas intraformacionais. Essa diferença de valores entre os conjuntos litológicos pode ser claramente observada ao longo das zonas de estruturas que atravessam diversos litotipos, como a região de zonas de bandas de deformação no bloco sul, a região de F1 e as estruturas do bloco central.

\section{DISCUSSÃO}

No afloramento estudado, as falhas principais (F1 e F2) se desenvolveram em regiões de elevada concentração de bandas de deformação, especialmente a falha F1, sendo encontrados nas regiões dessas falhas os maiores valores dos parâmetros de densidade de estruturas, junto à região de concentração de zonas de bandas de deformação no bloco sul. Em rochas porosas, a ocorrência de falhas associadas a bandas de deformação é destacada em diversos estudos, desde o trabalho pioneiro de Aydin e Johnson (1978). As bandas de deformação são reconhecidamente o principal elemento estrutural das zonas de dano de falhas nesse tipo de rocha (Fossen et al., 2017).

Os diferentes litotipos que compõem a Formação Resende exercem controle na distribuição das falhas e bandas de deformação, o que pôde ser reconhecido principalmente na região relativa ao bloco central. Próximo da base do afloramento, onde há um intervalo de arenitos médios a grossos, foi observado um número elevado de bandas de deformação e, em termos relativos, poucas falhas. Em posição estratigráfica superior aos arenitos, em um intervalo espesso de lutitos, foram detectadas somente falhas. Além disso, grande parte das falhas observadas nesse intervalo de lutitos não se propaga para os intervalos em posição estratigráfica superior. No bloco sul, esse controle também é verificado, uma vez que as zonas de bandas de deformação são mais largas nos arenitos médios a grossos e nos conglomerados, e se adelgaçam nos lutitos, nos arenitos lamosos e nas brechas intraformacionais.

O controle litológico observado na distribuição das falhas e bandas de deformação é destacado por Fossen et al. (2017), que evidenciam as variações de largura das zonas de bandas de deformação (clusters) ao atravessarem diferentes litotipos, sendo mais largas nos arenitos médios a grossos do que nos arenitos finos e siltitos, onde ocorrem como superfícies de deslizamento, assim como foi verificado no presente estudo.

Heynekamp et al. (1999) também apontam a granulometria dos sedimentos como o principal fator controlador da largura das zonas de dano, sendo mais larga onde a falha atravessa sedimentos ricos em areia e cascalho e mais restrita onde atravessa sedimentos ricos em argila e silte. Além disso, também destacam a influência da espessura das camadas e da distribuição das camadas com diferentes granulometrias. Em camadas com espessuras decimétricas, a zona de dano se mostrou mais larga do que em camadas com espessuras centimétricas. A espessura das camadas isoladamente, entretanto, não foi considerada um fator controlador, verificando-se que, quando a falha atravessa uma camada com espessura decimétrica, a granulometria dessa camada controla a espessura da zona de dano; já quando a falha atravessa uma sequência de camadas centimétricas com diferentes granulometrias, o que controla a espessura da zona de dano é a granulometria dominante no conjunto de camadas. Outros fatores, como o tipo, a geometria e a história evolutiva da falha, bem como a localização em relação à falha, são também considerados na literatura como elementos de controle da distribuição de falhas e bandas de deformação (Heynekamp et al., 1999; Schueller et al., 2013; Fossen et al., 2017).

Observou-se, ainda, o controle litológico na variação de espessuras das bandas de deformação comparando-se arenitos com diferentes granulometrias e graus de seleção, tomando como base os atributos obtidos nas áreas de amostragem em janelas retangulares $1 \mathrm{e} 2$. Nos arenitos grossos e conglomerados finos, moderadamente a mal selecionados, as bandas de deformação são mais espessas do que nos arenitos médios, moderadamente a bem selecionados. Fossen et al. (2007) relacionam a espessura das bandas de deformação com a granulometria dos arenitos em que se desenvolveram. Para os autores, bandas de desagregação possuem até $1 \mathrm{~mm}$ de espessura nos arenitos finos, podendo chegar a $5 \mathrm{~mm}$ nos arenitos médios e grossos, enquanto bandas cataclásticas apresentam cerca de $1 \mathrm{~mm}$ de espessura independentemente da granulometria dos arenitos. Ambos os tipos de bandas de deformação foram caracterizados por Rotava (2017) no afloramento investigado, sendo predominantes as bandas cataclásticas. A seleção dos grãos é apontada na literatura como um fator controlador do grau de catáclase nas bandas de deformação (Fossen et al., 2017), sendo maior quanto melhor for a seleção dos grãos. Dessa forma, de acordo com Fossen et al. $(2007,2017)$, quanto melhor selecionado e menor for a granulometria dos arenitos, as bandas de deformação tendem a ser menos espessas, corroborando o que foi observado em A1 e A2.

A configuração estrutural do afloramento, caracterizada por um gráben principal, e o conjunto de falhas identificado, de orientação NE-SW a ENE-WSW e movimentação 
normal, permitem relacionar o padrão de deformação descrito à fase E2, conforme já discutido em trabalhos anteriores realizados no afloramento (Maciel et al., 2017) e de acordo com os modelos evolutivos propostos para a Bacia de Volta Redonda (Sanson et al., 2006; Negrão et al., 2015) e para o RCSB (Riccomini et al., 2004). Esse padrão não é atribuído à fase E1, responsável pela formação da bacia, pois, de acordo com Maciel et al. (2017), a falha principal F2 também afeta os depósitos da Formação Pinheiral, de idade oligocênica. Além disso, os autores identificaram estrias indicativas de movimentação normal superpostas a estrias indicativas de movimentação oblíqua, relacionadas às fases de deformação transcorrentes miocênica (TS) e pleistocênica (TD). As bandas de deformação descritas no afloramento são classificadas, em sua maioria, como bandas cataclásticas, geradas por mecanismos de cisalhamento, principalmente, e de compactação (Rotava, 2017). Interpreta-se que essas estruturas não estão relacionadas geneticamente ao padrão de deformação distensiva predominante no afloramento, sugerindo-se que sua gênese está associada a fase(s) anterior(es) de deformação transcorrente - transcorrência sinistral E-W miocênica (TS) e/ou transcorrência dextral E-W pleistocênica (TD).

$\mathrm{O}$ fato de muitas das falhas normais presentes no afloramento, especialmente as falhas principais ( $\mathrm{F} 1 \mathrm{e} \mathrm{F} 2)$, estarem relacionadas com zonas de bandas de deformação, permite interpretar que a evolução dessas falhas teria ocorrido a partir da formação sequencial de bandas individuais, zonas de bandas (clusters) e superfícies de deslizamento, como no modelo proposto por Aydin e Johnson (1978). A formação sequencial das estruturas no caso do afloramento investigado é atribuída, no entanto, a sucessivas fases tectônicas, em que as bandas de deformação, relacionadas a fase(s) transcorrente(s), foram reativadas como falhas normais na fase E2.

\section{CONCLUSÕES}

As principais falhas identificadas (falhas F1 e F2) apresentam notável relação com as regiões do afloramento com as maiores densidades de bandas de deformação. Tais falhas são atribuídas à fase E2, desenvolvendo-se a partir de zonas de bandas de deformação que teriam sido originadas em fase(s) transcorrente(s) anterior(es).

A distribuição das estruturas de deformação no afloramento investigado, com exceção das falhas principais (F1 e F2), está diretamente relacionada aos litotipos em que ocorrem. Nos arenitos médios a grossos e nos conglomerados, verificam-se, preferencialmente, bandas de deformação ou zonas de bandas, compondo faixas de deformação mais largas do que nos lutitos, nos arenitos lamosos, nos arenitos finos e nas brechas intraformacionais, onde podem ocorrer como superfícies de deslizamento simples.
A localização em relação às falhas principais também exerce controle na distribuição das estruturas, uma vez que o bloco abatido, independentemente dos litotipos afetados, apresenta uma distribuição mais contínua das estruturas, reforçando o padrão de deformação típico de um regime distensivo.

Em uma escala mais abrangente, é sugerido que a distância para a borda de falha da bacia é um importante controle para o desenvolvimento das bandas de deformação no afloramento, uma vez que a densidade dessas estruturas aumenta em direção a sul, onde está localizada a borda falhada.

A caracterização da distribuição das estruturas de deformação em arenitos pouco consolidados e a identificação de seus possíveis controles irão contribuir para estudos de modelagem geológica e estrutural de reservatórios pouco consolidados e fraturados, como aqueles presentes nas bacias da margem continental do Sudeste do Brasil, tais como os reservatórios do Maastrichtiano das bacias de Campos e Santos. A definição de equações relacionando a frequência de estruturas de deformação com a distância ao núcleo de falha, bem como a utilização dos parâmetros de densidade como dados de entrada para a criação dos arcabouços estruturais dos modelos, são exemplos dessas possíveis contribuições.

\section{AGRADECIMENTOS}

Agradecemos ao Programa de Pós-graduação em Geologia da Universidade Federal do Rio de Janeiro (PPGL/UFRJ), à Coordenação de Aperfeiçoamento de Pessoal de Nível Superior (CAPES) e ao projeto de pesquisa e desenvolvimento Caracterização da deformação e de propriedades mecânicas e permoporosas de arenitos pouco consolidados (termo de Cooperação 0050.0102131.16.9 UFRJ/ Coppetec/ANP/Petrobras), o suporte em infraestrutura e financiamento. Aos colegas Verônica de Carvalho Batista, Thamirez Nascimento Bassi, Amanda Menezes Ricardo, Caio Gimenez Guimarães, Thaís Coelho Brêda, Leandro Neves Araújo, Diogo Rodrigues Reste, Aline Theophilo Silva, Jorge André Braz Souza, Emílio Velloso Barroso, Francisco Cézar Costa Nogueira, Francisco Hilario Rego Bezerra e Fabrizio Balsamo, o apoio e as valorosas discussões. Aos Srs. José Luiz de Paiva Leijoto e Robson de Paiva Leijoto a autorização de acesso ao terreno onde está localizado o afloramento investigado.

\section{REFERÊNCIAS}

Angelier, J. (1994). Fault slip analysis and paleostress reconstruction. In: P. L. Hancock (Ed.), Continental Deformation, p. 53-100. Oxford: Pergamon Press. 
Aydin, A., Johnson, A. M. (1978). Development of faults as zones of deformation bands and as slip surfaces in sandstone. Pure and Applied Geophysics, 116, 931-942. https://doi. org/10.1007/BF00876547

Delvaux, D., Sperner, B. (2003). New aspects of tectonic stress inversion with reference to the TENSOR program. In: D. A. Nieuwland (Ed.), New Insights into Structural Interpretation and Modelling, v. 212(1), p. 75-100. Londres: Geological Society, Special Publications. https://doi.org/10.1144/GSL. SP.2003.212.01.06

Dershowitz, W. S., Herda, H. H. (1992). Interpretation of fracture spacing and intensity. 33rd U. S. Symposium on Rock Mechanics, 757-766. Santa Fé: USRMS.

Fisher, Q. J., Knipe, R. J. (1998). Fault sealing processes in siliciclastic sediments. In: G. Jones, Q. J. Fisher, R. J. Knipe (Eds.), Faulting, Fault Sealing and Fluid Flow in Hydrocarbon Reservoirs, v. 147(1), p. 117-134. Londres: The Geological Society, Special Publications. https://doi. org/10.1144/GSL.SP.1998.147.01.08

Fossen, H., Schultz, R. A., Shipton, Z. K., Mair, K. (2007). Deformation bands in sandstone: a review. Journal of the Geological Society, 164(4), 755-769. https://doi. org/10.1144/0016-76492006-036

Fossen, H., Soliva, R., Ballas, G., Trzaskos, B., Cavalcante, C., Schultz, R. A. (2017). A review of deformation bands in reservoir sandstones: geometries, mechanisms and distribution. In: M. Ashton, S. J. Dee, O. P. Wennberg (Eds.), Subseismic-Scale Reservoir Deformation, v. 459(1), p. 9-33. Londres: The Geological Society, Special Publications. https://doi.org/10.1144/SP459.4

Galvão, M. S. (2018). O papel das falhas e bandas de deformação sobre o fabric dos arenitos da Formação Resende (Eoceno, Rift Continental do Sudeste do Brasil) e seu impacto sobre o comportamento hidromecânico. MS. Dissertação (Mestrado). Rio de Janeiro: Instituto de Geociências - UFRJ, 173 p.

Gibson, R. G. (1998). Physical character and fluid-flow properties of sandstone-derived fault zones. In: M. P. Coward, T. S. Daltaban, H. Johnson (Eds.), Structural Geology in Reservoir Characterization, v. 127(1), p. 83-97. Londres: The Geological Society, Special Publications. https://doi. org/10.1144/GSL.SP.1998.127.01.07

Heilbron, M., Almeida, J. C. H., Eirado Silva, L. G., Palermo, N., Duarte, B. P., Valladares, C. S., Ramos, R., Sanson, M., Guedes, E., Gontijopascutti, A. H., Nogueira, J. R., Valeriano,
C., Ribeiro, A., Ragatky, C. D., Miranda, A., Mello, C. L., Sanches, L., Roig, H. L., Dios, F. B., Fernadez, G., Neves, A., Guimarães, P., Dourado, F., Lacerda; V. G. (2007). Mapa Geológico e Nota Explicativa Integrada das Folhas Santa Rita do Jacutinga, Barra do Pirai, Volta Redonda e Angra dos Reis - escala 1:100.000. Brasília: Serviço Geológico do Brasil - CPRM, 173 p.

Heilbron, M., Eirado, L. G., Almeida, J. (2016). Geologia e recursos minerais do Estado do Rio de Janeiro: texto explicativo e mapa geológico e de recursos minerais escala 1:400.000. Brasília: Serviço Geológico do Brasil CPRM, $182 \mathrm{p}$.

Heynekamp, M. R., Goodwin, L. B., Mozley, P. S., Haneberg, W. C. (1999). Controls on fault-zone architecture in poorly lithified sediments, Rio Grande Rift, New Mexico: Implications for fault-zone permeability and fluid flow. In: W. C. Haneberg, P. S. Mozley, J. Casey Moore, L. B. Goodwin (Eds.), Faults and subsurface fluid flow in the shallow crust, v. 113, p. 27-51. Washington, D.C.: Geophysical Monograph Series. https://doi.org/10.1029/GM113p0027

Howell, J. A., Martinius, A. W., Good, T. R. (2014). The application of outcrop analogues in geological modelling: a review, present status and future outlook. In: A. W. Martinius, J.A. Howell, T. R. Good (Eds.), Sediment-Body Geometry and Heterogeneity: Analogue Studies for Modelling the Subsurface, v. 387(1), p. 1-25. Londres: The Geological Society, Special Publications. https://doi.org/10.1144/SP387.12

Maciel, I. B., Mello, C. L., Silva, A. T. (2017). Caracterização da deformação rúptil em afloramento da Formação Resende, Bacia de Volta Redonda, Estado do Rio de Janeiro. Geologia USP. Série Científica, 17(3), 113-124. https://doi.org/10.11606/ issn.2316-9095.v17-391

Negrão, A. P., Ramos, R. R. C., Mello, C. L., Sanson, M. S. R. (2015). Mapa geológico do Cenozoico da região da bacia de Volta Redonda (RJ, segmento central do Rifte Continental do Sudeste do Brasil): identificação de novos grábens e ocorrências descontínuas, e caracterização de estágios tectonossedimentares. Brazilian Journal of Geology, 45(2), 273-291. https://doi.org/10.1590/23174889201500020007

Pei, Y., Paton, D. A., Knipe, R. J., Wu, K. (2015). A review of fault sealing behaviour and its evaluation in siliciclastic rocks. Earth-Science Reviews, 150, 121-138. https://doi. org/10.1016/j.earscirev.2015.07.011

Priest, S. D. (1993). Discontinuity Analysis for Rock Engineering. Londres: Chapman e Hall. https://doi. org/10.1007/978-94-011-1498-1 
Ramos, R. R. C., Mello, C. L., Sanson, M. S. R. (2006). Revisão estratigráfica da Bacia de Resende, Rift Continental do Sudeste do Brasil, Estado do Rio de Janeiro. Geociências, 25(1), 59-69.

Riccomini, C. (1989). O Rift Continental do Sudeste do Brasil. Tese (Doutorado). São Paulo: Instituto de Geociências - USP, 319 p. https://doi.org/10.11606/T.44.1990. tde-18032013-105507

Riccomini, C., Sant'Anna, L. G., Ferrari, A. L. (2004). Evolução geológica do Rift Continental do Sudeste do Brasil. In: V. Mantesso-Neto, A. Bartorelli, C. D. R. Carneiro, B. B. Brito Neves (Eds.), Geologia do continente Sul-Americano: evolução da obra de Fernando Flávio Marques de Almeida, p. 383-405. São Paulo: Beca.

Rotava, I. (2017). Caracterização macroscópica e microscópica de bandas de deformação em arenitos da Formação Resende (Eoceno, Rift Continental do Sudeste do Brasil). Trabalho Final de Curso (Graduação). Rio de Janeiro: Instituto de Geociências - UFRJ, 55 p.

Sanson, M. S. R., Ramos, R. R. C., Mello, C. L. (2006). Bacias Sedimentares Brasileiras - Bacia de Volta Redonda. Phoenix, 88, 1-6.

Schueller, S., Braathen, A., Fossen, H., Tveranger, J. (2013). Spatial distribution of deformation bands in damage zones of extensional faults in porous sandstones: statistical analysis of field data. Journal of Structural Geology, 52, 148-162. https://doi.org/10.1016/j.jsg.2013.03.013

Vogel, S. N., Mello, C. L., Silva, A. T. (2019). Aspectos tomográficos e microtomográficos de feições de deformação rúptil em arenitos pouco consolidados da Formação Resende (Bacia de Volta Redonda-RJ). Anuário do Instituto de Geociências, 42(1), 759-768. http://doi. org/10.11137/2019_1_759_768

Watkins, H., Bond, C. E., Healy, D., Butler, R. W. H. (2015). Appraisal of fracture sampling methods and a new workflow to characterise heterogeneous fracture networks at outcrop. Journal of Structural Geology, 72, 67-82. https:// doi.org/10.1016/j.jsg.2015.02.001

Wibberley, C. A. J., Yielding, G., Di Toro, G. (2008). Recent advances in the understanding of fault zone internal structure: a review. In: C. A. J. Wibberley, W. Kurz, J. Imber, R. E. Holdsworth, C. Collettini (Eds.), The internal structure of fault zones: implications for mechanical and fluid-flow properties, v. 299(1), p. 5-33. Londres: The Geological Society, Special Publications. http://doi.org/10.1144/SP299.2

Zalán, P. V., Oliveira, J. A. B. (2005). Origem e evolução estrutural do Sistema de Riftes Cenozóicos do Sudeste do Brasil. Boletim de Geociências da Petrobras, 13(2), 269-300. 